OPEN ACCESS

Edited by:

Chandravanu Dash, Meharry Medical College, United States

Reviewed by: Lin Cheng,

The University of lowa, United States Gurudutt Pendyala, University of Nebraska Medical Center, United States

${ }^{*}$ Correspondence: Prasun K. Datta dattapk@temple.edu

Specialty section: This article was submitted to Pharmacogenetics and Pharmacogenomics, a section of the journal Frontiers in Pharmacology

Received: 04 July 2019 Accepted: 21 November 2019 Published: 13 December 2019

Citation:

Alam MA and Datta PK (2019) Epigenetic Regulation of Excitatory

Amino Acid Transporter 2 in Neurological Disorders.

Front. Pharmacol. 10:1510. doi: 10.3389/fphar.2019.01510

\section{Epigenetic Regulation of Excitatory Amino Acid Transporter 2 in Neurological Disorders}

\author{
Mohammad Afaque Alam and Prasun K. Datta* \\ Department of Neuroscience, Center for Comprehensive NeuroAIDS, Lewis Katz School of Medicine at Temple University, \\ Philadelphia, PA, United States
}

Excitatory amino acid transporter 2 (EAAT2) is the predominant astrocyte glutamate transporter involved in the reuptake of the majority of the synaptic glutamate in the mammalian central nervous system (CNS). Gene expression can be altered without changing DNA sequences through epigenetic mechanisms. Mechanisms of epigenetic regulation, include DNA methylation, post-translational modifications of histones, chromatin remodeling, and small non-coding RNAs. This review is focused on neurological disorders, such as glioblastoma multiforme (GBM), Alzheimer's disease (AD), amyotrophic lateral sclerosis (ALS), Parkinson's disease (PD), bipolar disorder (BD), and neuroHIV where there is evidence that epigenetics plays a role in the reduction of EAAT2 expression. The emerging field of pharmaco-epigenetics provides a novel avenue for epigenetics-based drug therapy. This review highlights findings on the role of epigenetics in the regulation of EAAT2 in different neurological disorders and discusses the current pharmacological approaches used and the potential use of novel therapeutic approaches to induce EAAT2 expression in neurological disorders using CRISPR/Cas9 technology.

\begin{abstract}
Keywords: glutamate, microRNA, excitatory amino acid transporter 2, DNA methyltransferase, histone
\end{abstract} deacetylase, CRISPR/Cas9

\section{INTRODUCTION}

The human excitatory amino acid transporter 2 (EAAT2) or glutamate transporter 1 (GLT-1) in the rodents is the primary glutamate transporter in the astrocytes (Rothstein et al., 1996; Sheldon and Robinson, 2007; Kim et al., 2011), and handles 90\% of total glutamate uptake in the CNS (Tanaka et al., 1997). The SLC1A2 (solute carrier family, member 2) gene, located on chromosome codes for EAAT2 in humans (Meyer et al., 1997), while in mouse, it is located on chromosome 2 and is known as glutamate transporter 1 (GLT1). The size of the human and mouse EAAT2 gene is $~ 11.7$ and $\sim 11.5 \mathrm{~kb}$, respectively, and both genes contain 11 exons (Figure 1A).

The promoter analysis of the human EAAT2 gene reveals that it harbors transcription factor binding sites for Nuclear factor kappa-B (NFKB), Specificity protein 1 (Sp1), cAMP responsive element binding protein (CREB), Ying-yang 1 (YY1), and peroxisome proliferator activated receptor (PPAR) response element (Su et al., 2003; Sitcheran et al., 2005; Zschocke et al., 2007; Romera et al., 2007; Allritz et al., 2010; Unger et al., 2012; Karki et al., 2014; Vartak-Sharma et al., 2014). Also, the proximal promoter harbors $\mathrm{CpG}$ islands at position -1472 to -1146 and -680 to -494 , with $17 \mathrm{CpG}$ and 15 CpG dinucleotides, respectively (Zschocke et al., 2007). The human EAAT2 cDNA harbors an unusually long 3'-UTR of 9684 bp (Kim et al., 2003). Sequence analysis shows that the 3'-UTR 


\section{A}
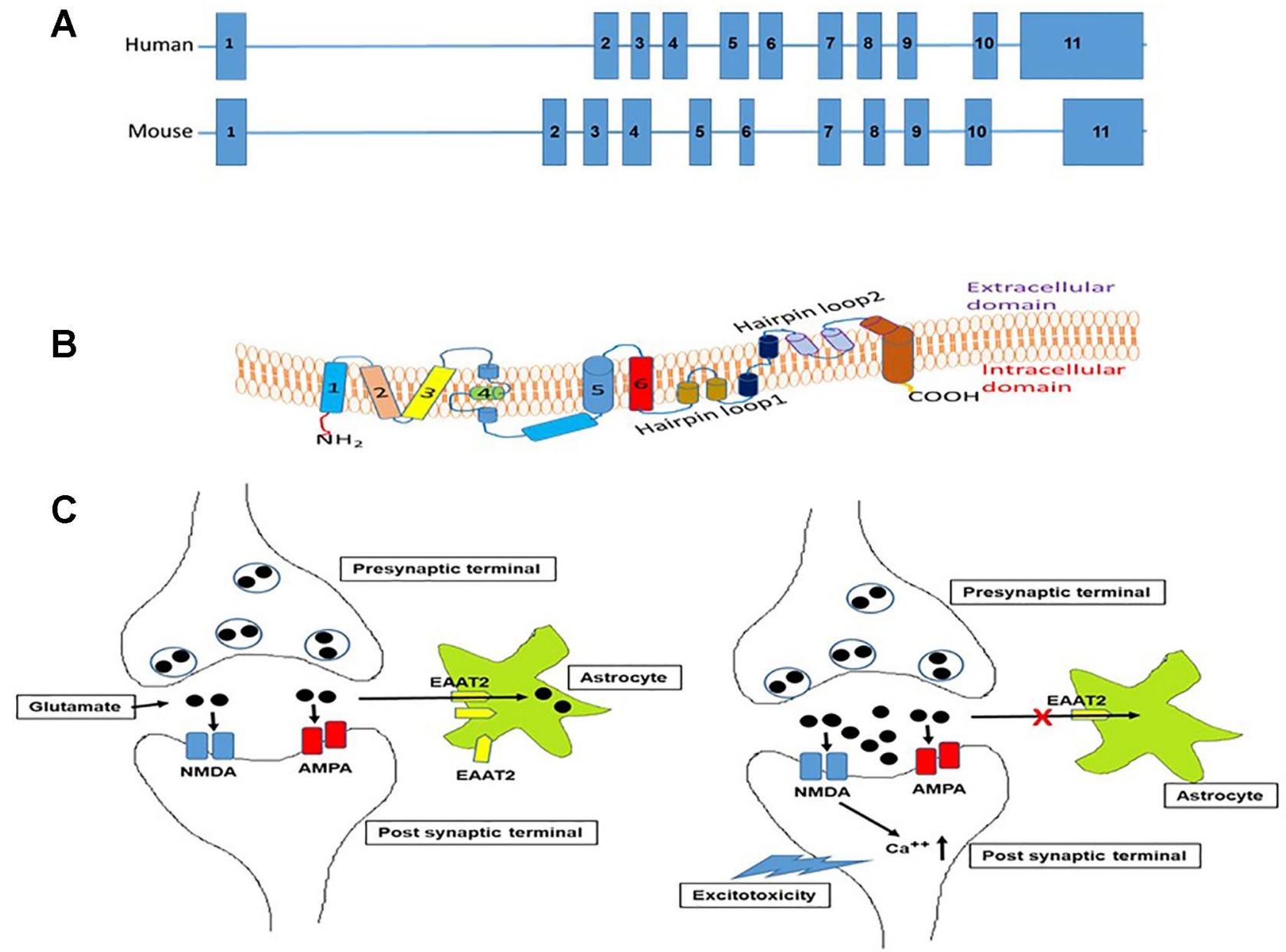

FIGURE 1 | (A). Schematic representation of the organization of introns and exons of SLC1A2 gene in human and mouse based on UCSC genome browser. The size of SLC1A2 gene is $11704 \mathrm{bp}$ in human and $11565 \mathrm{bp}$ in mouse. (B). Schematic depiction of the organization of EAAT2 in the plasma membrane as deduced from crystallographic data (Yernool et al., 2004) and adapted from Boston-Howes et al. (2006). The protein contains eight transmembrane domains and two helical hairpin loops (HP1) and (HP2). These hairpin structures are involved in transport of amino acids mainly -glutamate. (C). Schematic representation of the mechanism of glutamate-mediated excitotoxicity in the synaptic cleft due to dysregulation of EAAT2 expression in astrocytes. In normal scenario, depolarization of nerve terminal (presynaptic) glutamate is released from synaptic vesicles. Released glutamate then binds to ionotropic glutamate receptors (NMDA-R and AMPA-R) on the postsynaptic terminal that results in depolarization and action potential generation. Glutamate is then removed quickly from the synaptic cleft by astrocyte EAAT2 transporter to prevent the overstimulation of glutamate receptors. However, excessive glutamate accumulation in the synaptic cleft due to dysregulation of astrocyte EAAT2 expression causes overstimulation of NMDA and AMPA receptors that results in the build-up of intracellular $\mathrm{Ca}^{++}$ions leading to neuronal death or excitotoxicity.

of EAAT2 cDNA is nearly identical and conserved in human, macaque, rat, and mouse (Kim et al., 2003). This observation suggests that it is likely that EAAT2 mRNA expression can be regulated at the post-transcriptional level by miRNAs.

EAAT2 is a plasma membrane sodium-dependent, highaffinity amino acid transporter that mediates the uptake of L-glutamate (Arriza et al., 1994). In brief, the protein has eight transmembrane domains with the amino- and carboxyterminal located intracellularly (Figure 1B). It clears the excitatory neurotransmitter glutamate from the extracellular space at synapses in the brain (Rothstein et al., 1996). Glutamate clearance by astrocyte is critical for proper synaptic activation, and also glutamate is converted to glutamine and transported out of the astrocytes into neurons for reuse in glutamate synthesis (Erecińska and Silver, 1990). Furthermore, reuptake of glutamate by EAAT2 also prevents neuronal damage caused by excessive activation of NMDA receptors (Figure 1C), a phenomenon known as excitotoxicity (Olney and Sharpe, 1969).

\section{EPIGENETIC REGULATORS: THE WRITERS, READERS, AND ERASERS}

Epigenetics is defined as changes in gene expression without the involvement of changes in the DNA sequence. The epigenetic "writers" are enzymes such as DNA methyltransferases, histone 
lysine methyltransferases, protein arginine methyltransferases, and histone acetyltransferases that catalyze the addition of a functional group to a protein or nucleic acid (Gillette and Hill, 2015). The epigenetic "readers" are proteins or enzymes such as methyl CpG binding proteins, histone methylation readers, and histone acetylation readers that recognize methylated DNA, methylated lysine residues in proteins and acetylated histones, respectively. The epigenetic "erasers" are enzymes, such as ten-eleven translocation (TET) family of proteins, histone demethylases, and histone deacetylases (HDAC) that demethylate DNA, demethylate lysine residues on histone proteins, and deacetylate histone proteins (see reviews; Gillette and Hill, 2015; Biswas and Rao, 2018).

\section{DNA METHYLTRANSFERASES (DNMTS)}

DNMTs are classified into three categories, DNMT1, DNMT2, DNMT3 [DNMT3a, DNMT3b, and DNMT3L] (Lyko, 2018; Gujar et al., 2019). DNMT1 is involved in the maintenance methylation (Ren et al., 2018). DNMT3a and DNMT3b methylate cytosine residues in $\mathrm{CpG}$ island(s) and considered as de novo methyltransferases. DNMT1, DNMT3a, and DNMT3b catalyze the addition of a methyl group from $\mathrm{S}$-adenosylmethionine (SAM) to cytosine resulting in 5-mC. 5-mC acts as a stable transcriptional repressor (Kitsera et al., 2017). DNMT2 and DNMT3L are non-canonical family members, as they do not possess catalytic DNMT activity (Lyko, 2018).

\section{TEN-ELEVEN TRANSLOCATION}

DNA demethylation involves the TET family of methylcytosine dioxygenases that are $\alpha-K G$-dependent enzymes (Koivunen and Laukka, 2018). This family consists of TET1, TET2, and TET3, which participate in the conversion of 5-mC to 5-hmC to promote reversal of methylation (Ito et al., 2010; Melamed et al., 2018). Besides, studies have shown that Tet enzymes also catalyze the conversion of 5-hmC to 5-formylcytosine (5-fC), and 5-carboxylcytosine (5-caC). These modifications serve as DNA demethylation intermediates and are subject to deamination, glycosylase-dependent excision, and repair, resulting in a reversion to unmodified cytosine (Antunes et al., 2019).

\section{DNMT EXPRESSION IN ASTROCYTES}

In late-stage embryonic development in the brain, DNMT3a is ubiquitously expressed, while DNMT3b expression level decreases but remains high in comparison to early-stage embryos (Okano et al., 1999). The expression of DNMT1 and DNMT3a has been documented in rat brain cortical astrocytes (Zhang et al., 2014).

\section{TET EXPRESSION IN ASTROCYTES}

In the brain, NeuN positive neuronal cells express all forms of TETs (Kaas et al., 2013; Li et al., 2014). These observations are tune with reports that neuronal cells are enriched for $5 \mathrm{hmC}$
(Szulwach et al., 2011). TET1 expression has been documented in glial fibrillary acidic protein (GFAP) positive astrocytes in the adult mouse hippocampus (Kaas et al., 2013). It has been observed that TET enzymatic activity is inhibited by increased production of 2-hydroxyglutarate in gliomas as a consequence of oncogenic mutations in the metabolic regulators IDH1 (isocitrate dehydrogenase 1) and IDH2 (isocitrate dehydrogenase 2) (ReiterBrennan et al., 2018).

\section{HISTONE DEACETYLASES}

HDACs based on their amino acid sequence, organization of the domains, and catalytic dependence are grouped into four classes (de Ruijter et al., 2003). Class I, II, and IV HDACs are zinc-dependent, while class III are nicotinamide adenine dinucleotide $(\mathrm{NAD}+)$ dependent. The class I HDACs include HDAC1, $-2,-3$, and -8 , while class II includes HDAC4, -5, -6, $-7,-9$, and -10 , and class IV is represented by HDAC11 (de Ruijter et al., 2003). Class III HDACs include sirtuins 1-7 (SIRT1-7) that are structurally unrelated to the other HDACs (Carafa et al., 2016).

\section{HDAC EXPRESSION IN ASTROCYTES}

A comprehensive study was the first to demonstrate the expression of HDACs in rat brain using high-resolution in situ hybridization (ISH) coupled with immunohistochemistry in astrocytes, oligodendrocytes, neurons, and endothelial cells (Broide et al., 2007). The study showed that GFAP-positive astrocytes expressed HDAC3 to HDAC11 (Broide et al., 2007). However, a recent study reported that only HDAC1, 2, and 4 are expressed in rat astrocytes (Kalinin et al., 2013). HDAC $1,2,3$, and 8 are expressed in normal human astrocytes, and glioblastoma multiforme (GBM) derived astrocytic cell lines (Zhang et al., 2016).

\section{SIRTUINS EXPRESSION IN ASTROCYTES}

Among the class III HDACs, SIRT1 is the most conserved member of the sirtuin family of NAD+ dependent protein deacetylases (Cohen et al., 2004) and is predominantly a nuclear enzyme but also present in the mitochondria (Tang, 2016). SIRT1 is expressed in mouse (Li M et al., 2018), rat, and human astrocytes (Hu et al., 2017). SIRT2 is a cytoplasmic enzyme (Braidy et al., 2015), and its expression was observed in rat hippocampus and cerebral cortex. Unlike SIRT1, which is primarily a nuclear enzyme SIRT3, 4, 5 are mitochondrial enzymes (Jęśko et al., 2017; Sidorova-Darmos et al., 2018). The expression of SIRT3 was shown in rat astrocytes ( $\mathrm{Li} \mathrm{X}$ et al., 2018). SIRT4 is highly expressed in rat astrocytes (Komlos et al., 2013). It is reported that SIRT5 is expressed in rat striatum (Omonijo et al., 2014). Not much is known about the astrocyte-specific expression of SIRT6 and SIRT7, that are nuclear enzymes except for that fact that they are expressed in rat hippocampus and cerebral cortex (Braidy et al., 2015). 


\section{NONCODING RNA: miRNAs}

miRNAs are small noncoding RNAs (20-22 nucleotides) regulate gene expression by binding to seed sequences located in the 3'-UTR of mRNAs (He and Hannon, 2004; Bartel, 2009). The complementarity between the miRNA seed sequence and its target mRNA determines the fate of the mRNA resulting in either translational repression or mRNA cleavage (Guo et al., 2010). A single miRNA can regulate many different mRNAs or can bind to a single site or multiple sites within the 3 '-UTR of the mRNA.

\section{NEUROLOGICAL DISORDERS AND EAAT2 EXPRESSION}

In this section, we describe the various neurological disorders where dysregulation of EAAT2 expression have been reported. A summary of the epigenetic changes affecting EAAT2 gene is presented in Table 1. The epigenetic changes that are involved in EAAT2 expression is shown in Figure 2.

\section{GLIOBLASTOMA MULTIFORME (GBM)}

GBM, a WHO grade IV astrocytoma is an extremely aggressive, invasive, and destructive primary brain tumor in the adult population (Geraldo et al., 2019). Lee and co-workers demonstrated a strong negative correlation between the expression of Astrocyte Elevated Gene-1 (AEG-1), an oncogene, and EAAT2 by immunofluorescence analyses in human glioma tissue arrays (Lee et al., 2011). Dysregulation of EAAT2 expression is also seen in cell lines derived from tumors (Zschocke et al., 2007; Lee et al., 2011). In two different glioma cell lines, A172 and LN18 that lack EAAT2 expression profiling of DNA methylation by bisulfite sequencing revealed hypermethylation in both CpG islands of EAAT2 promoter (Zschocke et al., 2007).

\section{ALZHEIMER'S DISEASE (AD)}

$\mathrm{AD}$ is a chronic neurodegenerative disorder that contributes to $60 \%$ to $70 \%$ of dementia worldwide. Most forms of $\mathrm{AD}$ are sporadic, and less than $1 \%$ of all cases are familial AD. Earlyonset AD is caused by mutations of the genes for APP (amyloid

TABLE 1 | Epigenetic modifications involved in dysregulation of EAAT2 expression.

\begin{tabular}{|c|c|c|c|}
\hline Type of Epigenetic modification & Tissue/cell type & Effect on EAAT2/GLT-1 & References \\
\hline \multicolumn{4}{|l|}{ DNA methylation } \\
\hline Promoter CpG island methylation & Glioma cell lines. & Reduced EAAT2 mRNA expression. & Zschocke et al., 2007. \\
\hline Enhanced DNMT1 activity. & $\begin{array}{l}\text { Brain tissues of HIV-infected } \\
\text { methamphetamine users. }\end{array}$ & Increase in global DNA methylation. & Desplats et al., 2014. \\
\hline $\begin{array}{l}\text { Hypermethylation of CpG island in } \\
\text { promoter. }\end{array}$ & & Not determined. & Desplats et al., 2014. \\
\hline $\begin{array}{l}\text { Hypermethylation of } \mathrm{CpG} \text { island in } \\
\text { promoter region. }\end{array}$ & Blood DNA. & Not determined & Jia et al., 2017. \\
\hline CpG site demethylation. & Rat brain astrocytes. & Increase in GLT-1 mRNA expression. & Perisic et al., 2010. \\
\hline \multicolumn{4}{|l|}{ Histone modifications } \\
\hline $\begin{array}{l}\text { Overexpression of HDAC1 and }-3 \text { (class I), } \\
\text { and HDAC6 and }-7 \text { (class II). }\end{array}$ & Rat brain astrocytes. & Decrease in EAAT2 promoter activity. & Karki et al., 2014 \\
\hline $\begin{array}{l}\text { Coexpression of HDACs with YY1 or } \\
\text { NFKB. }\end{array}$ & Rat brain astrocytes. & Decrease in EAAT2 promoter activity. & Karki et al., 2014. \\
\hline \multirow{4}{*}{$\begin{array}{l}\text { HDAC inhibition (SAHA, TSA, Romidepsin). } \\
\text { HDAC inhibition (TSA). } \\
\text { HDAC inhibition (MC1568). }\end{array}$} & Rat brain astrocytes. & Increase in EAAT2 promoter activity. & Karki et al., 2014. \\
\hline & Glioma cell lines. & Increase in EAAT2 mRNA expression. & Zschocke et al., 2007. \\
\hline & Mouse glia. & $\begin{array}{l}\text { Increase in EAAT2 mRNA and protein } \\
\text { expression. }\end{array}$ & Lapucci et al., 2017. \\
\hline & Spinal cord of rodent model of ALS. & $\begin{array}{l}\text { Increase in EAAT2 mRNA and protein } \\
\text { expression. }\end{array}$ & \\
\hline
\end{tabular}

\section{Sirtuins}

SIRT5 knock-out.

Non coding RNA

miR-107.

miR-124a.

miR-124.

miR-218.

miR-146a
Mice brain cortex.

Nerve cell hypoxia/reoxygenation ( $H / R)$ injury.

Mice neurons.

Human neural precursor cells and astrocytes.

Dying motor neurons from rat model of ALS.

Glioma cell line and human fetal brain astrocytes.

Sumoylation
Spinal cord astrocytes from SOD1-

G93A transgenic mice model of ALS.
Reduced expression of EAAT2 mRNA.

Koronowski et al., 2018.

Inhibition of GLT-1 expression.

Yang et al., 2014.

Induction of GLT-1 expression in astrocytes.

Induction of EAAT2 expression.

Morel et al., 2013.

Lee et al., 2014.

Inhibition of EAAT2 expression in astrocytes.

Hoye et al., 2018.

Inhibition of EAAT2 expression in astrocytes.

Deshmane et al., 2018

Reduced plasma membrane EAAT2

Foran et al., 2014. expression due to retention of EAAT2 in the

cytoplasm. 


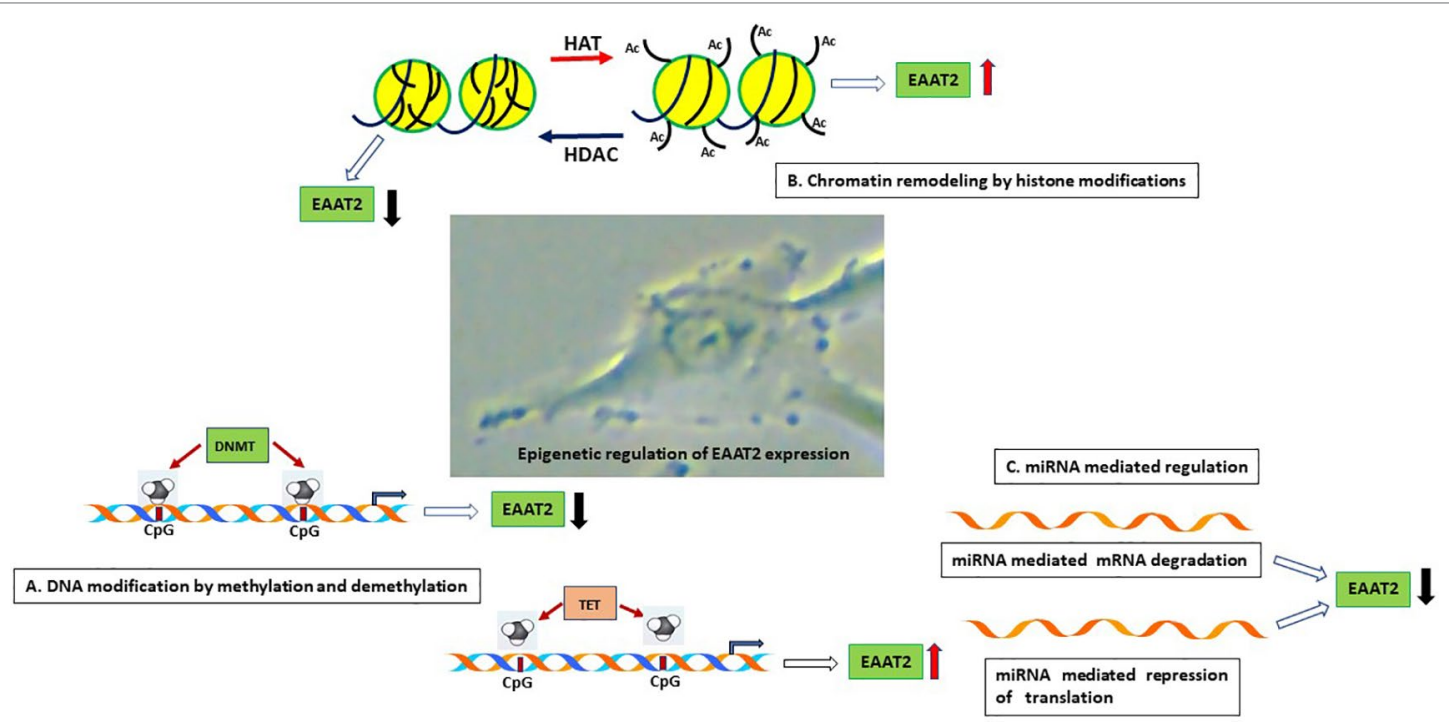

FIGURE 2 | Schematic representation of the epigenetic mechanisms that are involved in astrocyte EAAT2 expression. (A). DNA modification by methylation and demethylation. Hypermethylation of CpG islands on the EAAT2 promoter can repress transcription of EAAT2 gene by inhibiting binding of transcription factors. On the contrary, demethylation of DNA in CpG island can promote transcription factor interaction with DNA and EAAT2 gene transcription. (B). Chromatin remodeling by histone modifications. The observation that HDAC inhibitors induce EAAT2 expression demonstrate that HDAC activity inhibits EAAT2 expression, on the other hand, histone acetylation by HATs can lead to open chromatin and increased accessibility of transcription factors to open chromatin and induce EAAT2 expression. (C). miRNA mediated regulation. Binding of miRNA to the 3'-UTR of EAAT2 mRNA can result in miRNA mediated mRNA degradation or repression of translation resulting in reduced expression of EAAT2. HAT, Histone acetyltransferase; HDAC, Histone deacetylase; DNMT, DNA methyltransferase; TET, Ten eleven translocation enzyme.

precursor protein), PSEN1 (presenilin 1), and PSEN2 (presenilin 2) (Giau et al., 2019). The pathological hallmarks are $\beta$-amyloid plaques localized extracellularly and neurofibrillary tangles, which are localized intracellularly, especially in the frontal cortex and hippocampus (Pinheiro and Faustino, 2019). Studies have shown decreased EAAT2 protein expression in AD brains ( $\mathrm{Li}$ et al., 1997; Jacob et al., 2007). EAAT2 expression is reduced in astrocytes by oligomeric A $\beta$ by NFAT signaling (Abdul et al., 2009). Dysregulation of EAAT2 expression has been linked in the pathogenesis of AD in APPSw/Ind mice, a transgenic mouse of AD (Takahashi et al., 2015).

\section{AMYOTROPHIC LATERAL SCLEROSIS (ALS)}

ALS is a late-onset and devastating neurodegenerative disorder that is characterized by progressive degeneration of motor neurons in the motor cortex, spinal cord, and brainstem (Verber et al., 2019). Studies have shown that there is a loss of EAAT2 protein in the motor cortex and spinal cord in ALS patients (Rothstein et al., 1995). In the transgenic mice or rats expressing familial ALS-linked mutant SOD1 reduced expression of EAAT2 protein has also been observed (Bruijn et al., 1997; Bendotti et al., 2001; Howland et al., 2002). In addition, another epigenetic modulator, known as sumoylation was shown to regulate localization of EAAT2 expression in SOD1-G93A mouse model of inherited ALS, wherein the cytosolic carboxy-terminal domain is cleaved from EAAT2, conjugated to SUMO1, and results in the accumulation of
EAAT2 in the cytoplasm instead of expression in the plasma membrane (Foran et al., 2014).

\section{PARKINSON'S DISEASE (PD)}

$\mathrm{PD}$ is a complex neurodegenerative disorder that impacts the dopaminergic neurons located in the midbrain nucleus substantia nigra (Dauer and Przedborski, 2003). The pathological hallmark of $\mathrm{PD}$ is the accumulation of $\alpha$-synuclein oligomers to form Lewy bodies (Wong and Krainc, 2017). In PD, induced in mouse models by 6-hydroxydopamine injection into the nigrostriatal pathway (Chung et al., 2008) and 1-methyl-4-phenyl-1,2,3,6tetrahydropyridine (Holmer et al., 2005) EAAT2 expression is reduced. Studies have shown that high manganese (Mn) levels induce manganism, symptoms of which are similar to those of PD (Bowman et al., 2011). In this regard, Mn treatment of astrocytes inhibited EAAT2 expression by upregulating YY1 expression that repressed EAAT2 expression at the mRNA and protein level (Karki et al., 2014).

\section{BIPOLAR DISORDER (BD)}

$\mathrm{BD}$ is a complex neurobiological disease (Harrison et al., 2018). In $\mathrm{BD}$, both glial cells and neurons are affected and dysregulation of monoamines, altered glutamatergic neurotransmission, increase in oxidative stress, mitochondrial dysfunction, and neuroinflammation play a role in the etiology of the disease 
(Yuksel and Ongur, 2010; Data-Franco et al., 2017). It is reported that a T-to-G polymorphism in the SLC1A2 gene promoter affects EAAT2 expression in BD (Dallaspezia et al., 2012). A recent study using high resolution melting PCR (HRM-PCR) and thymine-adenine (TA) cloning reported that the SLC1A2 promoter region was hypermethylated in BD (Jia et al., 2017).

\section{HIV-ASSOCIATED NEUROCOGNITIVE DISORDER (HAND)}

HAND or NeuroHIV persists despite effective antiretroviral therapy (Saylor et al., 2016). HIV-1 and gp120 have been shown to inhibit EAAT2 expression in human fetal brain astrocyte (Wang et al., 2003). Studies using immunohistochemistry have demonstrated that in HAND-positive brain tissues, expression of EAAT2 is reduced in comparison to uninfected brain tissue (Xing et al., 2009). Furthermore, it was shown that treatment of human brain astrocytes with a pro-inflammatory cytokine IL- $1 \beta$, induced AEG-1 expression that, in turn, upregulated YY1 expression and inhibited EAAT2 transcription (Vartak-Sharma et al., 2014). Elucidation of global DNA methylation status in brain tissues of HIV-individuals who used methamphetamine showed increased levels of DNMT1 activity and also hypermethylation of CpG nucleotides in SLC1A2 promoter (Desplats et al., 2014).

\section{ROLE OF HDACS AND SIRTUINS IN EAAT2 EXPRESSION}

Overexpression of HDAC1 and -3 (class I), and HDAC6 and -7 (class II) was shown to inhibit EAAT2 promoter activity in rat astrocytes (Karki et al., 2014). In the same study, the coexpression of HDACs with YY1 or NFkB further attenuated EAAT2 promoter activity (Karki et al., 2014). There is a lack of information on the effect of SIRTs in the regulation of EAAT2 expression. A recent metabolomics study using SIRT5 knockout mice model showed dysregulation of glutamate levels in brain cortex and reduced expression of EAAT2 at mRNA level (Koronowski et al., 2018).

\section{ROLE OF MIRNA IN EAAT2 EXPRESSION}

The upregulation of miR-107 was shown to inhibit GLT-1 expression in a rodent model of nerve cell hypoxia/reoxygenation (H/R) injury (Yang et al., 2014). Our preliminary studies show that miR-146a reduces EAAT2 expression in U251 cells and human fetal brain astrocytes (Deshmane et al., 2018). A recent report demonstrated that murine neuronal miR-124a induces astroglial EAAT2 not by targeting EAAT2 3'-UTR but by indirectly modulating astrocyte-derived factors that regulate EAAT2 expression (Morel et al., 2013). Also, exosome-mediated delivery of miR-124 was shown to induce the expression of EAAT2 in human neural precursor cells and astrocytes (Lee et al., 2014). In a recent study, a novel mechanism of neurodegeneration in a rat model of ALS was described extracellular miR-218 released from dying motor neurons inhibited EAAT2 expression in astrocytes (Hoye et al., 2018).

\section{PHARMACO-EPIGENETIC STRATEGIES TO ACTIVATE EAAT2 EXPRESSION}

A successful approach in the treatment of neurodegenerative diseases where epigenetics regulate gene expression could be the use of therapeutic drugs that target epigenetic mechanisms, such as DNA methylation, chromatin, and histone modifications. In this regard, significant advancements have been made to develop drugs that can restore or alter epigenetic mechanisms. In this section, we highlight the findings reported so far with DNMT inhibitors and HDAC inhibitors in the restoration of EAAT2 expression in vitro and in vivo.

\section{DNMT INHIBITORS}

DNMT inhibitors prevent DNA methylation as a consequence reduce promoter hypermethylation, which leads to re-expression of silenced genes. DNMT inhibitors have been widely used as anticancer drugs since hypermethylation of promoters of tumor suppressor genes occurs in numerous cancers (Pfister and Ashworth, 2017). DNMT inhibitors that are approved by the US Food and Drug Administration (FDA) and widely used as anticancer drugs are nucleoside analogs. These are azacytidine (5-aza-deoxycytidine) (Sorm and Vesely, 1964; Christman, 2002) and decitabine (5-aza-2'-deoxycytidine) (Pliml and Sorm, 1964). In this regard, DNMT inhibitor azacytidine was shown to restore EAAT2 expression in a glioma cell line (Zschocke et al., 2007).

\section{HDAC INHIBITORS}

Among the four major structural families of HDAC inhibitors viz., short-chain aliphatic acids, hydroxamic acids, benzamides, and cyclic tetrapeptides and depsipeptide only the efficacy of short-chain aliphatic acids, hydroxamic acids, and cyclic tetrapeptides and depsipeptide have been evaluated in inducing EAAT2 expression.

Valproic acid (VPA short-chain aliphatic acid), an FDAapproved anti-epileptic agent and sodium butyrate that inhibits class I and II HDACs (Göttlicher et al., 2001) were reported to prevent manganese-induced inhibition of GLT1 expression in mice (Johnson et al., 2018a; Johnson et al., 2018b). VPA induced CpG site demethylation and acetylated histone H4 enrichment in the distal part of the GLT-1 promoter in rat astrocytes (Perisic et al., 2010).

Hydroxamic acids, Trichostatin A (TSA) (Yoshida et al., 1990) was shown to induce EAAT2 mRNA expression in glioma cells (Zschocke et al., 2007), and EAAT2 promoter activity in rodent astrocyte (Karki et al., 2014).

Suberoylanilide hydroxamic acid (SAHA), an FDA approved drug, also induced EAAT2 promoter activity in rodent astrocyte (Karki et al., 2014). 
Among the cyclic tetrapeptides and depsipeptide, Romidepsin has been shown to induce EAAT2 promoter activity (Karki et al., 2014). MC1568, a class II HDAC inhibitor, was reported to upregulate the expression of EAAT2 in vitro and also in the spinal cord of SOD1-G93A mice, a rodent model of ALS (Lapucci et al., 2017).

\section{POTENTIAL USE OF CRISPR/CAS9 FOR EAAT2 GENE EXPRESSION}

With the discovery of several genome editing technologies such as zinc-finger nucleases (ZFNs), transcription activatorlike effector nucleases (TALEN), and clustered regularly interspaced short palindromic repeat (CRISPR)/Cas9 system (Datta et al., 2016; Khalili et al., 2017), it is possible not only to edit genes but also activate genes (Hilton et al., 2015) that are epigenetically repressed. Since epigenetic modifying enzymes can be fused to the inactivated dCas9 (D10A mutation in RuvC and $\mathrm{H} 840 \mathrm{~A}$ in $\mathrm{HNH}$ nuclease domain), it is possible to target specific gene promoters using guide RNAs (Tadić et al., 2019) and thereby prevent off-target effects of either overexpression or knockdown of epigenetic modifying enzymes. In the context of EAAT2 gene activation, two CRISPR tools can be used. dCas 9 fused to (a) histone acetyltransferase p300 (dCas9-p300) activation domain (Hilton et al., 2015), and (b) DNA demethylase catalytic domain from the TET family
(Xu et al., 2016). In the former scenario, the recruitment of dCas9-p300 by guide RNAs can result in histone acetylation mediated EAAT2 gene transcription (Figure 3A), and in the latter situation, DNA hypermethylation of the EAAT2 gene CPG islands can potentially be reversed by targeted demethylation of cytosine residues using the Tet catalytic domain (Tet-CD) and guide RNA (Figure 3B). This strategy can be accomplished in vivo since several viral vectors, including adeno-associated virus, lentivirus, and adenovirus (Figure 3C), have been employed for delivery of Cas9 and gRNAs (Gori et al., 2015; Mout et al., 2017).

\section{CONCLUSIONS AND FUTURE DIRECTIONS}

A large body of evidence demonstrates the involvement of epigenetic mechanisms, including DNA methylation and histone modification at the pre-transcriptional level and miRNAs at the posttranscriptional level in the dysregulation of EAAT2 expression in numerous neurodegenerative diseases. The mechanisms may also act in concert while regulating EAAT2 expression. The involvement of other epigenetic features, including posttranslational histone modifications, including acetylation, methylation, and phosphorylation, in the regulation of EAAT2/GLT1 promoter activation in astrocytes remains to be investigated in future studies. With

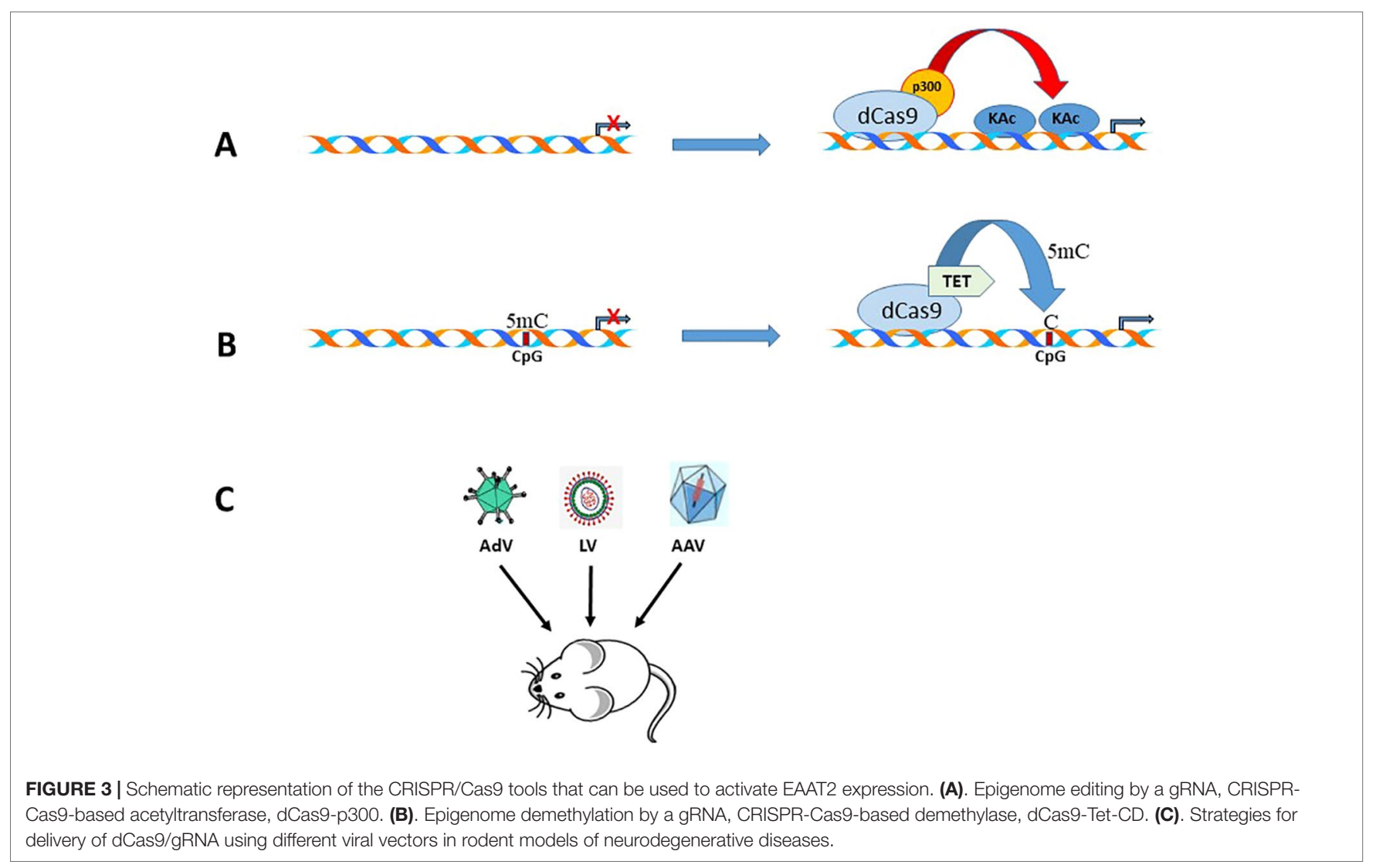


the development of new epigenetic drugs with increased sensitivity, specificity, and decreased toxicity it might be possible to upregulate EAAT2 expression in neurological disorders depending on the epigenetic modification that is involved in repression of EAAT2 expression. However, it is likely that in addition to gene-specific modulation, genome wide reactivation or inactivation of genes at random can have potentially deleterious effects. The proposed CRISPR/ Cas9 mediated EAAT2 gene regulation can, therefore, be employed in animal models to mitigate glutamate-mediated excitotoxicity.

\section{REFERENCES}

Abdul, H. M., Sama, M. A., Furman, J. L., Mathis, D. M., Beckett, T. L., Weidner, A. M., et al. (2009). Cognitive decline in Alzheimer's disease is associated with selective changes in calcineurin/NFAT signaling. J. Neurosci. 29, 12957-12969. doi: 10.1523/JNEUROSCI.1064-092009

Allritz, C., Bette, S., Figiel, M., and Engele, J. (2010). Comparative structural and functional analysis of the GLT-1/EAAT-2 promoter from man and rat. J. Neurosci. Res. 88, 1234-1241. doi: 10.1002/jnr.22303

Antunes, C., Sousa, N., Pinto, L., and Marques, C. J. (2019). TET enzymes in neurophysiology and brain function. Neurosci. Biobehav. Rev. 102, 337-344. doi: 10.1016/j.neubiorev.2019.05.006

Arriza, J. L., Fairman, W. A., Wadiche, J. I., Murdoch, G. H., Kavanaugh, M. P., and Amara, S. G. (1994). Functional comparisons of three glutamate transporter subtypes cloned from human motor cortex. J. Neurosci. 14, 5559-5569. doi: 10.1523/JNEUROSCI.14-09-055591994

Bartel, D. P. (2009). MicroRNAs: target recognition and regulatory functions. Cell 136, 215-233. doi: 10.1016/j.cell.2009.01.002

Bendotti, C., Tortarolo, M., Suchak, S. K., Calvaresi, N., Carvelli, L., Bastone, A., et al. (2001). Transgenic SOD1 G93A mice develop reduced GLT-1 in spinal cord without alterations in cerebrospinal fluid glutamate levels. J. Neurochem. 79, 37-46. doi: 10.1046/j.1471-4159.2001.00572.x

Biswas, S., and Rao, C. M. (2018). Epigenetic tools (The writers, the readers, and the erasers) and their implications in cancer therapy. Eur. J. Pharmacol. 837, 8-24. doi: 10.1016/j.ejphar.2018.08.021

Boston-Howes, W., Gibb, S. L., Williams, E. O., Pasinelli, P., Brown, R. H.Jr., and Trotti, D. (2006). Caspase-3 cleaves and inactivates the glutamate transporter EAAT2. J. Biol. Chem. 281, 14076-14084. doi: 10.1074/jbc.M600653200

Bowman, A. B., Kwakye, G. F., Hernandez, E. H., and Aschner, M. (2011). Role of manganese in neurodegenerative diseases. J. Trace Elem. Med. Biol. 25, 191203. doi: 10.1016/j.jtemb.2011.08.144

Braidy, N., Poljak, A., Grant, R., Jayasena, T., Mansour, H., Chan-Ling, T., et al. (2015). Differential expression of sirtuins in the aging rat brain. Front. Cell Neurosci. 9, 167. doi: 10.3389/fncel.2015.00167

Broide, R. S., Redwine, J. M., Aftahi, N., Young, W., Bloom, F. E., and Winrow, C. J. (2007). Distribution of histone deacetylases 1-11 in the rat brain. J. Mol. Neurosci. 31, 47-58. doi: 10.1007/BF02686117

Bruijn, L. I., Becher, M. W., Lee, M. K., Anderson, K. L., Jenkins, N. A., Copeland, N. G., et al. (1997). ALS-linked SOD1 mutant G85R mediates damage to astrocytes and promotes rapidly progressive disease with SOD1-containing inclusions. Neuron 18, 327-338. doi: 10.1016/S0896-6273(00)80272-X

Carafa, V., Rotili, D., Forgione, M., Cuomo, F., Serretiello, E., Hailu, G. S., et al. (2016). Sirtuin functions and modulation: from chemistry to the clinic. Clin. Epigenet. 8, 61. doi: 10.1186/s13148-016-0224-3

Christman, J. K. (2002). 5-Azacytidine and 5-aza-20-deoxycytidine as inhibitors of DNA methylation: mechanistic studies and their implications for cancer therapy. Oncogene 21, 5483-5495. doi: 10.1038/sj.onc.1205699

Chung, E. K., Chen, L. W., Chan, Y. S., and Yung, K. K. (2008). Downregulation of glial glutamate transporters after dopamine denervation in the striatum of 6-hydroxydopamine-lesioned rats. J. Comp. Neurol. 511, 421-437. doi: 10.1002/ cne. 21852

\section{AUTHOR CONTRIBUTIONS}

MAA contributed to writing the initial draft of the manuscript and illustrations. PD contributed to writing the review and editing.

\section{FUNDING}

PD was supported by the National Institutes of Health through grants from National Institute of Drug Abuse, 5R01DA033213, and in part by 5 P01DA037830-05.

Cohen, H. Y., Miller, C., Bitterman, K. J., Wall, N. R., Hekking, B., Kessler, B., et al. (2004). Calorie restriction promotes mammalian cell survival by inducing the SIRT1 deacetylase. Science 305, 390-392. doi: 10.1126/science.1099196

Dallaspezia, S., Poletti, S., Lorenzi, C., Pirovano, A., Colombo, C., and Benedetti, F. (2012). Influence of an interaction between lithium salts and a functional polymorphism in SLC1A2 on the history of illness in bipolar disorder. Mol. Diagn. Ther. 16, 303-309. doi: 10.1007/s40291-012-0004-5

Data-Franco, J., Singh, A., Popovic, D., Ashton, M., Berk, M., Vieta, E., et al. (2017). Beyond the therapeutic shackles of the monoamines: new mechanisms in bipolar disorder biology. Prog. Neuropsychopharmacol. Biol. Psychiatry 72, 73-86. doi: 10.1016/j.pnpbp.2016.09.004

Datta, P. K., Kaminski, R., Hu, W., Pirrone, V., Sullivan, N. T., Nonnemacher, M. R., et al. (2016). HIV-1 Latency and eradication: past, present and future. Curr. HIV Res. 14, 431-441. doi: 10.2174/1570162X14666160324125536

Dauer, W., and Przedborski, S. (2003). Parkinson's disease: mechanisms and models. Neuron 39, 889-909. doi: 10.1016/S0896-6273(03)00568-3

de Ruijter, A. J., van Gennip, A. H., Caron, H. N., Kemp, S., and van Kuilenburg, A. B. (2003). Histone deacetylases (HDACs): characterization of the classical HDAC family. Biochem. J. 370, 737-749. doi: 10.1042/bj20021321

Deshmane, S., Li, C., Kirby, L., and Datta, P. K. (2018). Regulation of glutamate transporter, EAAT2 by IL- $1 \beta$ and the impact of IL- $1 \beta$ and morphine on hippocampal physiology. J. NeuroVirol. 24 (1), s23-s24. doi: 10.1007/ s13365-018-0619-3

Desplats, P., Dumaop, W., Cronin, P., Gianella, S., Woods, S., Letendre, S., et al. (2014). Epigenetic alterations in the brain associated with HIV-1 infection and methamphetamine dependence. PloS One 9, e102555. doi: 10.1371/journal. pone. 0102555

Erecińska, M., and Silver, I. A. (1990). Metabolism and role of glutamate in mammalian brain. Prog. Neurobiol. 35, 245-296. doi: 10.1016/0301-0082(90)90013-7

Foran, E., Rosenblum, L., Bogush, A., Pasinelli, P., and Trotti, D. (2014). Sumoylation of the astroglial glutamate transporter EAAT2 governs its intracellular compartmentalization. Glia 62, 1241-1253. doi: 10.1002/ glia.22677

Göttlicher, M., Minucci, S., Zhu, P., Krämer, O. H., Schimpf, A., Giavara, S., et al. (2001). Valproic acid defines a novel class of HDAC inhibitors inducing differentiation of transformed cells. EMBO J. 20, 6969-6978. doi: 10.1093/ emboj/20.246969

Geraldo, L. H. M., Garcia, C., da Fonseca, A. C. C., Dubois, L. G. F., de Sampaio, E., Spohr, T. C. L., et al. (2019). Glioblastoma therapy in the age of molecular medicine. Trends Cancer 5, 46-65. doi: 10.1016/j.trecan.2018.11.002

Giau, V. V., Bagyinszky, E., Yang, Y. S., Youn, Y. C., An, S. S. A., and Kim, S. Y. (2019). Genetic analyses of early-onset Alzheimer's disease using next generation sequencing. Sci. Rep. 9, 8368. doi: 10.1038/s41598-019-44848-2

Gillette, T. G., and Hill, J. A. (2015). Readers, writers, and erasers: chromatin as the whiteboard of heart disease. Circ. Res. 116, 1245-1253. doi: 10.1161/ CIRCRESAHA.116.303630

Gori, J. L., Hsu, P. D., Maeder, M. L., Shen, S., Welstead, G. G., and Bumcrot, D. (2015). Delivery and specificity of CRISPR-Cas9 genome editing technologies for human gene therapy. Hum. Gene Ther. 26, 443-451. doi: 10.1089/ hum.2015.074 
Gujar, H., Weisenberger, D. J., and Liang, G. (2019). The roles of human DNA methyltransferases and their isoforms in shaping the epigenome. Genes (Basel) 10 (2), E172. doi: 10.3390/genes10020172

Guo, H., Ingolia, N. T., Weissman, J. S., and Bartel, D. P. (2010). Mammalian microRNAs predominantly act to decrease target mRNA levels. Nature 466, 835-840. doi: 10.1038/nature09267

Harrison, P. J., Geddes, J. R., and Tunbridge, E. M. (2018). The emerging neurobiology of bipolar disorder. Trends Neurosci. 41, 18-30. doi: 10.1016/j. tins.2017.10.006

He, L., and Hannon, G. J. (2004). MicroRNAs: small RNAs with a big role in gene regulation. Nat. Rev. Genet. 5, 522-531. doi: 10.1038/nrg1379

Hilton, I. B., D’Ippolito, A. M., Vockley, C. M., Thakore, P. I., Crawford, G. E., Reddy, T. E., et al. (2015). Epigenome editing by a CRISPR-Cas9-based acetyltransferase activates genes from promoters and enhancers. Nat. Biotechnol. 33, 510-517. doi: 10.1038/nbt3199

Holmer, H. K., Keyghobadi, M., Moore, C., and Meshul, C. K. (2005). L-dopainduced reversal in striatal glutamate following partial depletion of nigrostriatal dopamine with 1-methyl-4-phenyl-1,2,3,6-tetrahydropyridine. Neuroscience 136, 333-341. doi: 10.1016/j.neuroscience.2005.08.003

Howland, D. S., Liu, J., She, Y., Goad, B., Maragakis, N. J., Kim, B., et al. (2002). Focal loss of the glutamate transporter EAAT2 in a transgenic rat model of SOD1 mutant-mediated amyotrophic lateral sclerosis (ALS). Proc. Natl. Acad. Sci. U. S. A. 99, 1604-1609. doi: 10.1073/pnas.032539299

Hoye, M. L., Regan, M. R., Jensen, L. A., Lake, A. M., Reddy, L. V., Vidensky, S., et al. (2018). Motor neuron-derived microRNAs cause astrocyte dysfunction in amyotrophic lateral sclerosis. Brain. 141, 2561-2575. doi: 10.1093/brain/ awy 182

Hu, G., Liao, K., Yang, L., Pendyala, G., Kook, Y., Fox, H. S., et al. (2017). TatMediated induction of miRs-34a and -138 promotes astrocytic activation via downregulation of SIRT1: implications for aging in HAND. J. Neuroimmune Pharmacol. 12, 420-432. doi: 10.1007/s11481-017-9730-0

Ito, S., D’Alessio, A. C., Taranova, O. V., Hong, K., Sowers, L. C., and Zhang, Y. (2010). Role of Tet proteins in $5 \mathrm{mC}$ to $5 \mathrm{hmC}$ conversion, ES-cell self-renewal and inner cell mass specification. Nature 466, 1129-1123. doi: 10.1038/nature09303

Jęśko, H., Wencel, P., Strosznajde, R. P., and Strosznajder, J. B. (2017). Sirtuins and their roles in brain aging and neurodegenerative disorders. Neurochem. Res. 42 , 876-890. doi: 10.1007/s11064-016-2110-y

Jacob, C. P., Koutsilieri, E., Bartl, J., Neuen-Jacob, E., Arzberger, T., Zander, N., et al. (2007). Alterations in expression of glutamatergic transporters and receptors in sporadic Alzheimer's disease. J. Alzheimers Dis. 11, 97-116. doi: 10.3233/JAD-2007-11113

Jia, Y. F., Choi, Y., Ayers-Ringler, J. R., Biernacka, J. M., Geske, J. R., Lindberg, D. R., et al. (2017). Differential SLC1A2 promoter methylation in bipolar disorder with or without addiction. Front. Cell Neurosci. 11, 217. doi: 10.3389/ fncel.2017.00217

Johnson, J.Jr., Pajarillo, E., Karki, P., Kim, J., Son, D. S., Aschner, M., et al. (2018a). Valproic acid attenuates manganese-induced reduction in expression of GLT-1 and GLAST with concomitant changes in murine dopaminergic neurotoxicity. Neurotoxicology 67, 112-120. doi: 10.1016/j.neuro.2018.05.001

Johnson, J.Jr., Pajarillo, E. A. B., Taka, E., Reams, R., Son, D. S., Aschner, M., et al. (2018b). Valproate and sodium butyrate attenuate manganese-decreased locomotor activity and astrocytic glutamate transporters expression in mice. Neurotoxicology 64, 230-239. doi: 10.1016/j.neuro.2017.06.007

Kaas, G. A., Zhong, C., Eason, D. E., Ross, D. L., Vachhani, R. V., Ming, G. L., et al. (2013). TET1 controls CNS 5-methylcytosine hydroxylation, active DNA demethylation, gene transcription, and memory formation. Neuron 79, 10861093. doi: 10.1016/j.neuron.2013.08.032

Kalinin, S., Polak, P. E., Lin, S. X., Braun, D., Guizzetti, M., Zhang, X., et al. (2013). Dimethyl fumarate regulates histone deacetylase expression in astrocytes. J. Neuroimmunol. 263 (1-2), 13-19. doi: 10.1016/j.jneuroim.2013.07.007

Karki, P., Webb, A., Smith, K., Johnson, J.Jr., Lee, K., Son, D. S., et al. (2014). Yin Yang 1 is a repressor of glutamate transporter EAAT2, and it mediates manganese-induced decrease of EAAT2 expression in astrocytes. Mol. Cell Biol. 34, 1280-1289. doi: 10.1128/MCB.01176-13

Khalili, K., White, M. K., and Jacobson, J. M. (2017). Novel AIDS therapies based on gene editing. Cell Mol. Life Sci. 74, 2439-2450. doi: 10.1007/s00018-017-2479-Z

Kim, K., Lee, S. G., Kegelman, T. P., Su, Z. Z., Das, S. K., Dash, R., et al. (2011). Role of excitatory amino acid transporter-2 (EAAT2) and glutamate in neurodegeneration: opportunities for developing novel therapeutics. J. Cell. Physiol. 226, 2484-2493. doi: 10.1002/jcp.22609

Kim, S. Y., Chao, W., Choi, S. Y., and Volsky, D. J. (2003). Cloning and characterization of the 3 '-untranslated region of the human excitatory amino acid transporter 2 transcript. J. Neurochem. 86, 1458-1467. doi: 10.1046/j. 1471-4159.2003.01958.x

Kitsera, N., Allgayer, J., Parsa, E., Geier, N., Rossa, M., Carell, T., et al. (2017). Functional impacts of 5-hydroxymethylcytosine, 5-formylcytosine, and 5-carboxycytosine at a single hemi-modified $\mathrm{CpG}$ dinucleotide in a gene promoter. Nucleic Acids Res. 45, 11033-11042. doi: 10.1093/nar/gkx718

Koivunen, P., and Laukka, T. (2018). The TET enzymes. Cell Mol. Life Sci. 75, 1339-1348. doi: 10.1007/s00018-017-2721-8

Komlos, D., Mann, K. D., Zhuo, Y., Ricupero, C. L., Hart, R. P., Liu, A. Y., et al. (2013). Glutamate dehydrogenase 1 and SIRT4 regulate glial development. Glia 61, 394-408. doi: 10.1002/glia.22442

Koronowski, K. B., Khoury, N., Morris-Blanco, K. C., Stradecki-Cohan, H. M., Garrett, T. J., and Perez-Pinzon, M. A. (2018). Metabolomics based identification of SIRT5 and protein kinase C epsilon regulated pathways in brain. Front. Neurosci. 12, 32. doi: 10.3389/fnins.2018.00032

Lapucci, A., Cavone, L., Buonvicino, D., Felici, R., Gerace, E., Zwergel, C., et al. (2017). Effect of class II HDAC inhibition on glutamate transporter expression and survival in SOD1-ALS mice. Neurosci. Lett. 656, 120-125. doi: 10.1016/j. neulet.2017.07.033

Lee, S. G., Kim, K., Kegelman, T. P., Dash, R., Das, S. K., Choi, J. K., et al. (2011). Oncogene AEG-1 promotes glioma-induced neurodegeneration by increasing glutamate excitotoxicity. Cancer Res. 71, 6514-6523. doi: 10.1158/0008-5472. CAN-11-0782

Lee, H. K., Finniss, S., Cazacu, S., Xiang, C., and Brodie, C. (2014). Mesenchymal stem cells deliver exogenous miRNAs to neural cells and induce their differentiation and glutamate transporter expression. Stem Cells Dev. 23, 28512861. doi: 10.1089/scd.20140146

Li, S., Mallory, M., Alford, M., Tanaka, S., and Masliah, E. (1997). Glutamate transporter alterations in Alzheimer disease are possibly associated with abnormal APP expression. J. Neuropathol. Exp. Neurol. 56, 901-911. doi: 10.1097/00005072-199708000-00008

Li, X., Wei, W., Zhao, Q. Y., Widagdo, J., Baker-Andresen, D., Flavel, C. R., et al. (2014). Neocortical Tet3-mediated accumulation of 5-hydroxymethylcytosine promotes rapid behavioral adaptation. Proc. Natl. Acad. Sci. U. S. A. 111, 7120 7125. doi: 10.1073/pnas.1318906111

Li, M. Z., Zheng, L. J., Shen, J., Li, X. Y., Zhang, Q., Bai, X., et al. (2018). SIRT1 facilitates amyloid beta peptide degradation by upregulating lysosome number in primary astrocytes. Neural Regener. Res. 13, 2005-2013. doi: 10.4103/1673-5374.239449

Li, X. H., Liu, S. J., Liu, X. Y., Zhao, H. Y., Yang, M. G., Xu, D. X., et al. (2018). Expression of SIRT3 in various glial cell types in the periventricular white matter in the neonatal rat brain after hypoxia. Tissue Cell. 52, 1-8. doi: 10.1016/j.tice.2018.03.004

Lyko, F. (2018). The DNA methyltransferase family: a versatile toolkit for epigenetic regulation. Nat. Rev. Genet. 19, 81-92. doi: 10.1038/nrg.2017.80

Melamed, P., Yosefzon, Y., David, C., Tsukerman, A., and Pnueli, L. (2018). Tet enzymes, variants, and differential effects on function. Front. Cell Dev. Biol. 6, 22. doi: $10.3389 /$ fcell.2018.00022

Meyer, T., Ludolph, A. C., Morkel, M., Hagemeier, C., and Speer, A. (1997). Genomic organization of the human excitatory amino acid transporter gene GLT-1. Neuroreport 8, 775-777. doi: 10.1097/00001756-199702100-00039

Morel, L., Regan, M., Higashimori, H., Ng, S. K., Esau, C., Vidensky, S., et al. (2013). Neuronal exosomal miRNA-dependent translational regulation of astroglial glutamate transporter GLT1. J. Biol. Chem. 288, 7105-7116. doi: 10.1074/jbc.M112.410944

Mout, R., Ray, M., Lee, Y. W., Scaletti, F., and Rotello, V. M. (2017). In vivo delivery of CRISPR/Cas9 for therapeutic gene editing: progress and challenges. Bioconjug. Chem. 28, 880-884. doi: 10.1021/acs.bioconjchem.7b00057

Okano, M., Bell, D. W., Haber, D. A., and Li, E. (1999). DNA methyltransferases Dnmt3a and Dnmt3b are essential for de novo methylation and mammalian development. Cell. 99, 247-257. doi: 10.1016/S0092-8674(00)81656-6

Olney, J. W., and Sharpe, L. G. (1969). Brain lesions in an infant rhesus monkey treated with monosodium glutamate. Science 166, 386-388. doi: 10.1126/ science. 166.3903 .386 
Omonijo, O., Wongprayoon, P., Ladenheim, B., McCoy, M. T., Govitrapong, P., Jayanthi, S., et al. (2014). Differential effects of binge methamphetamine injections on the mRNA expression of histone deacetylases (HDACs) in the rat striatum. Neurotoxicology 45, 178-184. doi: 10.1016/j.neuro.2014.10.008

Perisic, T., Zimmermann, N., Kirmeier, T., Asmus, M., Tuorto, F., Uhr, M., et al. (2010). Valproate and amitriptyline exert common and divergent influences on global and gene promoter-specific chromatin modifications in rat primary astrocytes. Neuropsychopharmacology 35 (3), 792-805. doi: 10.1038/ npp.2009.188

Pfister, S. X., and Ashworth, A. (2017). Marked for death: targeting epigenetic changes in cancer. Nat. Rev. Drug Discovery 16 (4), 241-263. doi: 10.1038/ nrd.2016.256

Pinheiro, L., and Faustino, C. (2019). Therapeutic strategies targeting Amyloid- $\beta$ in Alzheimer's disease. Curr. Alzheimer Res. 16, 418-452. doi: 10.2174/156720 5016666190321163438

Pliml, J., and Sorm, F. (1964). Synthesis of $2^{2}$-deoxy-D-ribofuranosyl-5azacytosine. Coll. Czech Chem. Commun. 1964, 29:2576-2577. doi: 10.1135/ cccc19642576

Reiter-Brennan, C., Semmler, L., and Klein, A. (2018). The effects of 2-hydroxyglutarate on the tumorigenesis of gliomas. Contemp. Oncol. (Pozn) 22, 215-222. doi: 10.5114/wo.2018.82642

Ren, W., Gao, L., and Song, J. (2018). Structural basis of DNMT1 and DNMT3Amediated DNA methylation. Genes (Basel) 9 (12), E620. doi: 10.3390/ genes 9120620

Romera, C., Hurtado, O., Mallolas, J., Pereira, M. P., Morales, J. R., Romera, A., et al. (2007). Ischemic preconditioning reveals that GLT1/EAAT2 glutamate transporter is a novel PPARgamma target gene involved in neuroprotection. J. Cereb. Blood Flow Metab. 27, 1327-1338. doi: 10.1038/sj.jcbfm.9600438

Rothstein, J. D., Van Kammen, M., Levey, A. I., Martin, L. J., and Kuncl, R. W. (1995). Selective loss of glial glutamate transporter GLT-1 in amyotrophic lateral sclerosis. Ann. Neurol. 38 (1), 73-84. doi: 10.1002/ana.410380114

Rothstein, J. D., Dykes-Hoberg, M., Pardo, C. A., Bristol, L. A., Jin, L., Kuncl, R. W., et al. (1996). Knockout of glutamate transporters reveals a major role for astroglial transport in excitotoxicity and clearance of glutamate. Neuron 16, 675-686. doi: 10.1016/S0896-6273(00)80086-0

Saylor, D., Dickens, A. M., Sacktor, N., Haughey, N., Slusher, B., Pletnikov, M., et al. (2016). HIV-associated neurocognitive disorder-pathogenesis and prospects for treatment. Nat. Rev. Neurol. 12, 234-248. doi: 10.1038/nrneurol.2016.27

Sheldon, A. L., and Robinson, M. B. (2007). The role of glutamate transporters in neurodegenerative diseases and potential opportunities for intervention. Neurochem. Int. 51, 333-355. doi: 10.1016/j.neuint.2007.03.012

Sidorova-Darmos, E., Sommer, R., and Eubanks, J. H. (2018). The role of SIRT3 in the brain under physiological and pathological conditions. Front. Cell Neurosci. 12, 196. doi: 10.3389/fncel.2018.00196

Sitcheran, R., Gupta, P., Fisher, P. B., and Baldwin, A. S. (2005). Positive and negative regulation of EAAT2 by NF-kappaB: a role for N-myc in TNFalphacontrolled repression. EMBO J. 24, 510-520. doi: 10.1038/sj.emboj.7600555

Sorm, F., and Vesely, J. (1964). The activity of a new antimetabolite, 5-azacytidine, against lymphoid leukaemia in ak mice. Neoplasma 11, 123-130.

Su, Z. Z., Leszczyniecka, M., Kang, D. C., Sarkar, D., Chao, W., Volsky, D. J., et al. (2003). Insights into glutamate transport regulation in human astrocytes: cloning of the promoter for excitatory amino acid transporter 2 (EAAT2). Proc. Natl. Acad. Sci. U. S. A. 100, 1955-1960. doi: 10.1073/pnas.0136555100

Szulwach, K. E., Li, X., Li, Y., Song, C. X., Wu, H., Dai, Q., et al. (2011). 5-hmCmediated epigenetic dynamics during postnatal neurodevelopment and aging. Nat. Neurosci. 14, 1607-1616. doi: 10.1038/nn2959

Tadić, V., Josipović, G., Zoldoš, V., and Vojta, A. (2019). CRISPR/Cas9based epigenome editing: an overview of dCas9-based tools with special emphasis on off-target activity. Methods 164-165, 109-119. doi: 10.1016/j. ymeth.2019.05.003

Takahashi, K., Kong, Q., Lin, Y., Stouffer, N., Schulte, D. A., Lai, L., et al. (2015). Restored glial glutamate transporter EAAT2 function as a potential therapeutic approach for Alzheimer's disease. J. Exp. Med. 212, 19-332. doi: 10.1084/ jem.20140413

Tanaka, K., Watase, K., Manabe, T., Yamada, K., Watanabe, M., Takahashi, K., et al. (1997). Epilepsy and exacerbation of brain injury in mice lacking the glutamate transporter GLT-1. Science 276, 699-1702. doi: 10.1126/science.276.53191699
Tang, B. L. (2016). Sirt1 and the mitochondria. Mol. Cells 239, 87-95. doi: 10.14348 /molcells. 20162318

Unger, T., Lakowa, N., Bette, S., and Engele, J. (2012). Transcriptional regulation of the GLAST/EAAT-1 gene in rat and man. Cell Mol. Neurobiol. 32, 539-547. doi: 10.1007/s10571-011-9790-2

Vartak-Sharma, N., Gelman, B. B., Joshi, C., Borgamann, K., and Ghorpade, A. (2014). Astrocyte elevated gene-1 is a novel modulator of HIV-1-associated neuroinflammation via regulation of nuclear factor- $\mathrm{kB}$ signaling and excitatory amino acid transporter-2 repression. J. Biol. Chem. 289, 19599-19612. doi: 10.1074/jbc.M114.567644

Verber, N. S., Shepheard, S. R., Sassani, M., McDonough, H. E., Moore, S. A., Alix, J. J. P., et al. (2019). Biomarkers in motor neuron disease: a state of the art review. Front. Neurol. 10, 291. doi: 10.3389/fneur.2019.00291

Wang, Z., Pekarskaya, O., Bencheikh, M., Chao, W., Gelbard, H. A., Ghorpade, A., et al. (2003). Reduced expression of glutamate transporter EAAT2 and impaired glutamate transport in human primary astrocytes exposed to HIV-1 or gp120. Virology 312, 60-73. doi: 10.1016/S0042-6822(03)00181-8

Wong, Y. C., and Krainc, D. (2017). a-synuclein toxicity in neurodegeneration: mechanism and therapeutic strategies. Nat. Med. 23, 1-13. doi: 10.1038/ $\mathrm{nm} 4269$

Xing, H. Q., Hayakawa, H., Gelpi, E., Kubota, R., Budka, H., and Izumo, S. (2009). Reduced expression of excitatory amino acid transporter 2 and diffuse microglial activation in the cerebral cortex in AIDS cases with or without HIV encephalitis. J. Neuropathol. Exp. Neurol. 68, 199-209. doi: 10.1097/ NEN.0b013e31819715df

Xu, X., Tao, Y., Gao, X., Zhang, L., Li, X., Zou, W., et al. (2016). CRISPR-based approach for targeted DNA demethylation. Cell Discovery 2, 16009. doi: 10.1038/celldisc.2016.9

Yang, Y., Gozen, O., Vidensky, S., Robinson, M. B., and Rothstein, J. D. (2010). Epigenetic regulation of neuron-dependent induction of astroglial synaptic protein GLT1. Glia 58, 277-286. doi: 10.1002/glia.20922

Yang, Z. B., Zhang, Z., Li, T. B., Lou, Z., Li, S. Y., Yang, H., et al. (2014). Up-regulation of brain-enriched miR-107 promotes excitatory neurotoxicity through downregulation of glutamate transporter-1 expression following ischaemic stroke. Clin. Sci. (Lond) 127, 679-689. doi: 10.1042/CS20140084

Yernool, D., Boudker, O., Jin, Y., and Gouaux, E. (2004). Structure of a glutamate transporter homologue from Pyrococcus horikoshii. Nature 431, 811-818. doi: 10.1038/nature03018

Yoshida, M., Kijima, M., Akita, M., and Beppu, T. (1990). Potent and specific inhibition of mammalian histone deacetylase both in vivo and in vitro by trichostatin A. J. Biol. Chem. 265, 17174-17179.

Yuksel, C., and Ongur, D. (2010). Magnetic resonance spectroscopy studies of glutamate-related abnormalities in mood disorders. Biol. Psychiatry 68, 785794. doi: 10.1016/j.biopsych.2010.06.016

Zhang, X., Kusumo, H., Sakharkar, A. J., Pandey, S. C., and Guizzetti, M. (2014). Regulation of DNA methylation by ethanol induces tissue plasminogen activator expression in astrocytes. J. Neurochem. 128, 344-349. doi: 10.1111/ jnc. 12465

Zhang, Z., Wang, Y., Chen, J., Tan, Q., Xie, C., Li, C., et al. (2016). Silencing of histone deacetylase 2 suppresses malignancy for proliferation, migration, and invasion of glioblastoma cells and enhances temozolomide sensitivity. Cancer Chemother. Pharmacol. 78, 1289-1296. doi: 10.1007/s00280-016-3188-2

Zschocke, J., Allritz, C., Engele, J., and Rein, T. (2007). DNA methylation dependent silencing of the human glutamate transporter EAAT2 gene in glial cells. Glia 55, 663-674. doi: 10.1002/glia.20497

Conflict of Interest: The authors declare that the research was conducted in the absence of any commercial or financial relationships that could be construed as a potential conflict of interest.

Copyright ( 2019 Alam and Datta. This is an open-access article distributed under the terms of the Creative Commons Attribution License (CC BY). The use, distribution or reproduction in other forums is permitted, provided the original author(s) and the copyright owner(s) are credited and that the original publication in this journal is cited, in accordance with accepted academic practice. No use, distribution or reproduction is permitted which does not comply with these terms. 